\title{
ESTUDO DA DIVERSIDADE ALFA DE TRÊS FAMÍLIAS DE DÍPTEROS MUSCOIDES CALIPTRADOS DE INTERESSE FORENSE EM ÁREA URBANA DE FEIRA DE SANTANA
}

\author{
Jéssica Silva Santos $^{1}$; Freddy Ruben Bravo Quijano ${ }^{2}$ \\ 1. Bolsista PROBIC/CNPq, Graduando em Biologia, Universidade Estadual de Feira de Santana, e-mail: \\ jyssantos.54@gmail.com.br \\ 2. Orientador, Departamento de Biologia, Universidade Estadual de Feira de Santana, e-mail: \\ $\underline{\text { fbravo@uefs.br }}$
}

PALAVRAS-CHAVE: Inventário; Insecta; Diptera.

\section{INTRODUÇÃO}

Os dípteros caliptrados das famílias Sarcophagidae, Calliphoridae, Muscidae e Fanniidae são essenciais para entomologia forense, por utilizarem material orgânico em decomposição para alimentação e ovi/larviposição (Oliveira-Costa, 2008).

Na região Neotropical são conhecidas 207 espécies de dípteros muscóides de interesse forense, é o Brasil mostrou a maior diversidade 159 espécies (Alves et al. 2014). Na região do Semiárido são conhecidas 45 espécies destas quatro famílias de dípteros caliptrados (Alves et al., 2014) e para Feira de Santana apenas 20 espécies de Calliphoridae, Muscidae e Fanniidae foram listadas por MONTEIRO et al. (2008), trabalho realizado em três áreas urbanas do município.

Com o objetivo de suprir a falta de informação na região e município, realizouse este trabalho para propor uma lista de espécies de três famílias de muscóides (Calliphoridae, Muscidae e Fanniidae) encontradas na área urbana no bairro da Conceição I em Feira de Santana, BA.

\section{MATERIAL E MÉTODOS OU METODOLOGIA (ou equivalente)}

O projeto foi realizado numa área urbana da cidade de Feira de Santana, numa antiga fazenda no bairro da Conceição I (12 $\left.14^{\circ} 08.2^{\prime \prime S} 38^{\circ} 56^{\prime} 12.9^{\prime \prime O}\right)$. Foram colocadas quatro armadilhas fabricadas seguindo o modelo de Hwang \& Turner (2005). As iscas e o tempo da coleta seguiu a metodologia de D'Almeida \& Fraga (2007). As coletas foram realizadas bimensalmente de julho de 2015 a maio de 2016, totalizando 06 coletas. Os espécimes capturados foram colocados em álcool $70 \%$ para posterior identificação laboratório. As análises estatísticas foram realizadas com o programa EstimateS® 7.0 (Colwell, 2004).

\section{RESULTADOS E/OU DISCUSSÃO (ou Análise e discussão dos resultados)}

Foram coletados 2.241 espécimes das três famílias de Diptera caliptrados de interesse forense. Foram identificadas 18 espécies, sendo que quatro delas foram somente identificadas até gênero (Tab. 1).

Crysomyia albiceps foi a espécie mais abundante nas coletas em Feira de Santana, com 390 espécimes. No trabalho de Monteiro et al. (2008), também, em Feira de Santana obtiveram resultado semelhante, sendo que $C$. albiceps foi a segunda espécie mais abundante. Esta espécie foi mais abundante em março, com 165 indivíduos. É importante salientar que na semana da coleta do mês de março houve queimadas no local das coleta com um grande número de espécimes desta espécie nas armadilhas. Não há registro de correlação desses dípteros e queimadas que explique seu aumento neste mês. No entanto, segundo Otsuka (2008), diz que esta espécie tem uma correlação positiva a temperaturas elevadas, explicando, assim, a sua abundancia nos meses de verão (janeiro-março). Preferencialmente, $C$. albiceps consome carcaças, mas quando o 
recurso torna-se escasso, ela muda seu comportamento tornando-se predador facultativo de outras larvas de outros dípteros (Faria et al., 1999). Segundo Otsuka (2008), este comportamento é à base da sua correlação negativa com diferentes famílias de dípteros. Esses dados ajudam a explicar o grande aumento dessa espécie e a diminuição de outras famílias nesse período.

Atherigona orientalis, é a segunda espécie mais abundante em todas as coletas e a primeira ao desconsiderar março, possui uma preferência pela carne em decomposição e também pelas frutas para a oviposição (D’Almeida, 1988), sendo este segundo substrato pouco procurado por outros muscóides. $\mathrm{O}$ fato de todas as armadilhas ficarem embaixo ou próximas a árvores frutíferas, provavelmente contribuiu para a sua abundância, mas também proporcionou a queda no mês de janeiro e março, já que foram os meses que tiveram o período de seca e queimadas. Segundo D'Almeida (1983) esta espécie de muscídeo prefere áreas habitadas o que pode explicar o maior número de espécimes nas coletas já que estas foram realizadas em área antropizada.

Tabela 1: Lista de espécies de dípteros caliptrados de três famílias de interesse forense por mês de coleta em Feira de Santana.

\begin{tabular}{|c|c|c|c|c|c|c|c|}
\hline Espécies & Julho & Setembro & Novembro & Janeiro & Março & Maio & Total \\
\hline \multicolumn{8}{|l|}{ Familia Calliphoridae } \\
\hline $\begin{array}{l}\text { Calliphora vicina Robineau- } \\
\text { Desvoidy, } 1851\end{array}$ & 0 & 0 & 25 & 12 & 38 & 19 & 94 \\
\hline $\begin{array}{c}\text { Chloroprocta idioidea }( \\
\text { Robineau-Desvoidy, 1830) }\end{array}$ & 5 & 0 & 20 & 9 & 42 & 6 & 82 \\
\hline $\begin{array}{l}\text { Chrysomya mecellaria( } \\
\text { Fabricius, 1794) }\end{array}$ & 0 & 0 & 4 & 30 & 9 & 6 & 49 \\
\hline $\begin{array}{c}\text { Chrysomya } \\
\text { albiceps(Wiedeman, 1819) }\end{array}$ & 9 & 29 & 63 & 94 & 165 & 30 & 390 \\
\hline $\begin{array}{l}\text { Chrysomya megacephala } \\
\text { (Wiedemann), }\end{array}$ & 0 & 0 & 59 & 40 & 0 & 16 & 115 \\
\hline $\begin{array}{l}\text { Chrysomya putoria } \\
\text { (wiedeman, 1818) }\end{array}$ & 0 & 0 & 0 & 6 & 9 & 0 & 15 \\
\hline $\begin{array}{c}\text { Lucilia eximia (Wiedeman, } \\
\text { 1819) }\end{array}$ & 41 & 26 & 25 & 65 & 20 & 49 & 226 \\
\hline \multicolumn{8}{|l|}{ Família Fanniidae } \\
\hline Fannia pusio (Wiedemann) & 65 & 30 & 40 & 14 & 4 & 55 & 208 \\
\hline $\begin{array}{c}\text { Fannia } \\
\text { obscurinervis }(\text { Stein,1900) }\end{array}$ & 5 & 1 & 0 & 1 & 0 & 1 & 8 \\
\hline $\begin{array}{l}\text { Fannia canicularis ( } \\
\text { Linnaeus, 1761) }\end{array}$ & 58 & 24 & 8 & 6 & 0 & 10 & 106 \\
\hline $\begin{array}{c}\text { Fannia trimaculata (Stein, } \\
1898)\end{array}$ & 67 & 25 & 26 & 27 & 0 & 30 & 175 \\
\hline \multicolumn{8}{|l|}{ Família Muscidae } \\
\hline $\begin{array}{l}\text { Atherigoma orientalis } \\
\text { Schiner, } 1868\end{array}$ & 64 & 89 & 52 & 8 & 6 & 58 & 277 \\
\hline $\begin{array}{c}\text { Musca domestica Linnaeus, } \\
1758\end{array}$ & 70 & 69 & 36 & 20 & 0 & 25 & 220 \\
\hline Ophyra sp. 1 & 0 & 0 & 3 & 9 & 0 & 0 & 12 \\
\hline Ophyra sp. 2 & 0 & 10 & 1 & 0 & 0 & 1 & 12 \\
\hline Ophyra sp. 3 & 0 & 0 & 0 & 0 & 1 & 3 & 4 \\
\hline $\begin{array}{c}\text { Synthesiomya nudiseta } \\
\text { (Wulp) }\end{array}$ & 80 & 22 & 3 & 6 & 0 & 18 & 129 \\
\hline \multirow[t]{2}{*}{ Brontae sp. 1} & 39 & 18 & 22 & 0 & 0 & 40 & 119 \\
\hline & & & & & & $\begin{array}{l}\text { Total } \\
\text { geral }\end{array}$ & 2.241 \\
\hline
\end{tabular}

Figura 1. Número de espécimes de cada família em cada mês de coleta em Feira de Santana. Os números correspondem aos meses de coleta: $1=$ Julho; $2=$ setembro; $3=$ novembro; $4=$ janeiro; $5=$ março, $6=$ maio. 


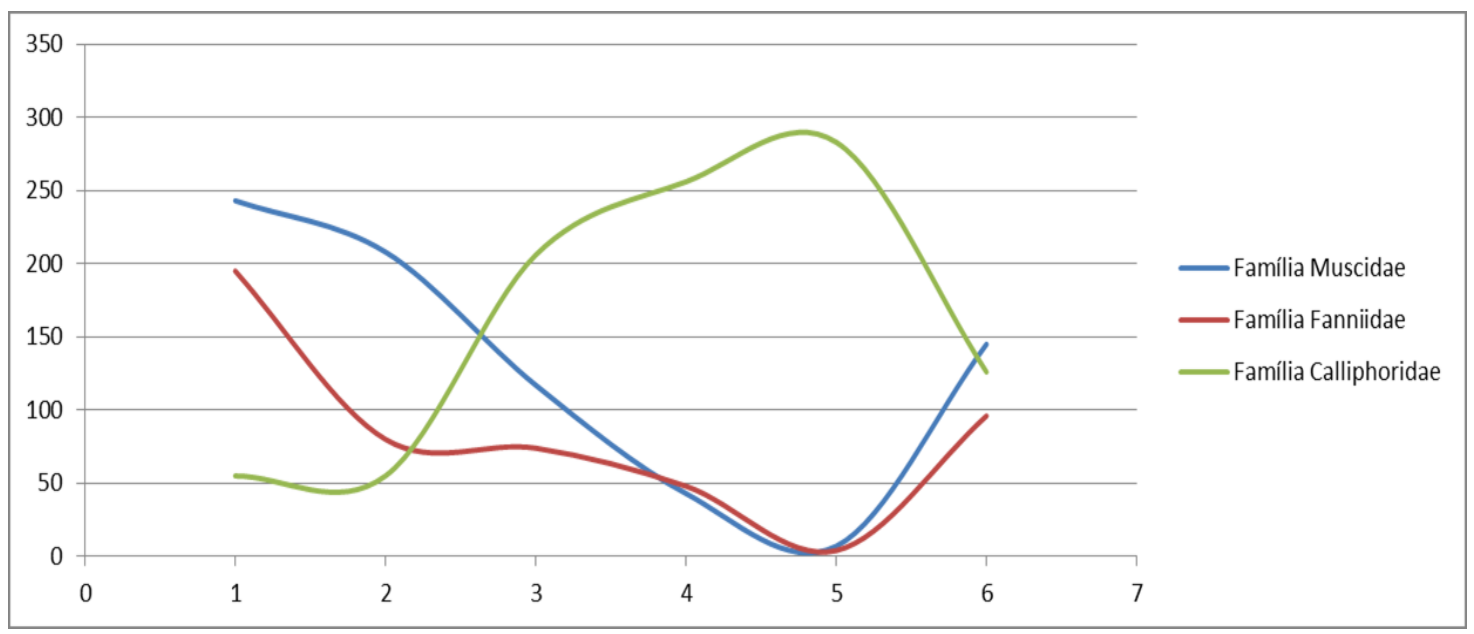

Como visto na Figura 1, quando mais se aproxima o período da seca, que é entre dezembro e fevereiro, a quantidade de espécimes de Muscidae e Fanniidae decai e só volta a aumentar próximo e durante o inverno (julho-setembro). No mês de dezembro a março Feira de Santana apresentou temperaturas acima de $30^{\circ}$ C. Nos estudos de Weigert et al. (2002) e de Marchiori \& Prado (1999) Muscidae e Fanniidae mostraram interações negativas a temperaturas elevadas, já que a $33^{\circ} \mathrm{C}$ prejudica a taxa reprodutiva de Fanniidae e a $35^{\circ} \mathrm{C}$ a taxa de viabilidade do ovo de Muscidae é baixa. Estes dados explicam o fato da queda de Muscidae e Fanniidae no mês de janeiro e março.

Figura 2: Curva do coletor ilustrando a riqueza acumulada de espécies durante as coletas na área de estudo em Feira de Santana

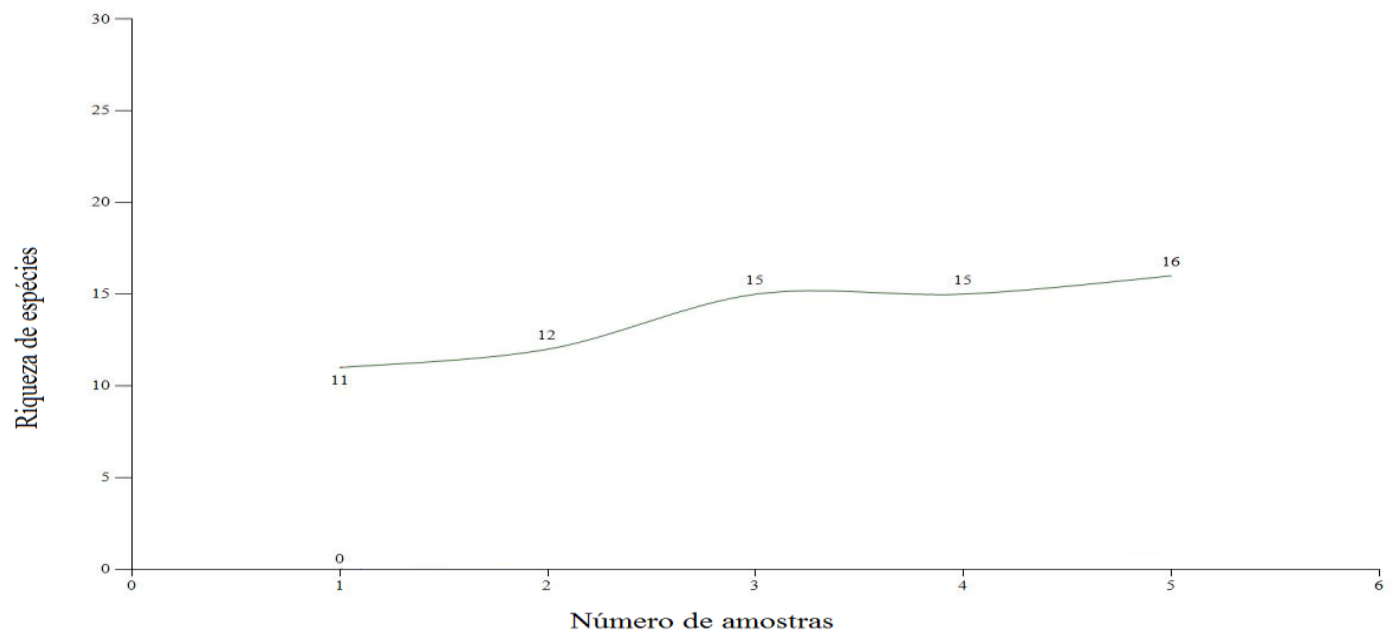

A curva do coletor, neste trabalho, não se estabiliza, mostrando que o esforço amostral realizado não foi suficiente para que a assíntota se estabilize. Nota-se que a curva ainda esta em crescimento.

\section{CONSIDERAÇÕES FINAIS (ou Conclusão)} espécimes

- A família mais rica em número de espécimes foi Calliphoridae com 971

- Neste trabalho, as famílias Muscidae e Fanniidae mostraram que tem uma relação negativa com o período de seca, decaindo em riqueza e diversidade neste período (entre dezembro e fevereiro), e subindo quando se aproxima do período chuvoso. 
- No quesito diversidade e riqueza, a família Calliphoridae, foi a que tem a melhor adaptação a períodos de seca. Sendo a espécie Chrysomya albiceps a espécie mais abundante no período da seca (janeiro - março), mostrando uma interação positiva com esse período.

- A curva do coletor relata que o números de amostras não é suficiente para obter a riqueza total do local.

\section{REFERÊNCIAS}

ALVES, A.C.F., W. DOS SANTOS; A. J. CREÃO-DUARTE. 2014. Diptera (Insecta) de importância forense da região Neotropical. Entomotropica 29: 77-94.

Colwell, R.K., 2004.[online] EstimateS, Version 7.0: Statistical Estimation of Species Richness and Shared Species from Samples (Software and User's Guide). Freeware for Windows and Mac OS. Homepage: http://viceroy.eeb.uconn.edu/EstimateS/.

D’ALMEIDA, J. M.; M.B. FRAGA. 2007. Efeito de diferentes iscas da atração de Califorídeos (Diptera) no Campus do Valonguinho, Universidade Federal Fluminense, Niterói, RJ, Brasil. Revista Brasileira de Parasitologia Veterinária 16: 199-204.

D’ALMEIDA, J.M. 1983. Sinantropia em dípteros muscóides na região metropolitana do Rio de Janeiro, UFRJ,Itaguaí, Rio de Janeiro, Tese de Mestrado, $193 p$.

D’ALMEIDA, J.M.; J.R. Almeida. 1998. Nichos tróficos em dípteros caliptrados, no Rio de Janeiro, RJ. Revista Brasileira de Biologia 58: 563-570.

FARIA, L.D.B., L. ORSI, L.A. TRINCA; W. GODOY. 1999. Larval predation by Chrysomya albiceps on Cochliomyia macellaria, Chrysomya megacephala and Chrysomya putoria. Entomologia Experimentalis et Applicata 90:149-155.

HWANG, C., TURNER, B.D. 2005. Spatial and temporal variability of necrophagous Diptera from urban to rural areas. Med. Vet. Entomol. 19, 379-391.

MARCHIORI C.H.; A.P PRADO. 1999. Tabelas de vida de Fannia pusio (Wied.) (Diptera: Fanniidae). An. Soc. Entomol. Bras. 28 (3): 557-563

MONTEIRO, T.T., E.N. SILVA; F.R. BRAVO. 2014. Levantamento Taxonômico e Sazonalidade de Calliphoridae, Muscidae e Fanniidae (Insecta: Diptera) em Feira de Santana, Bahia, Brasil. EntomoBrasilis, 7 (3): 171-177.

OLIVEIRA-COSTA, J. 2003. Entomologia Forense - Quanto os insetos são Vestígios. Millenium, 257 p.

OTSUKA, H. 2008. Sinantropia e sazonalidade de moscas varejeiras (Diptera: Calliphoridae) no Sudeste do Brasil: visões ecológica, médica, veterinária e forense.

WEIGERT, S. C., FIGUEIREDO, M. R. C., LOEBMANN, D., NUNES, J. A. R. \& SANTOS, L.G. 2002. Influência da temperature e do tipo de substrato na produção de larvas de Musca domestica Linnaeus, 1758 (Diptera, Muscidae). Revista Brasileira de Zootecnia, 31: 1886-1889. 